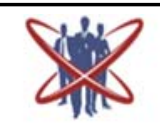

open acoess Joural International Journal of Emerging Trends in Science and Technology DOI: https://dx.doi.org/10.18535/ijetst/v7i1.02

\title{
Original Research Article \\ Patterns of Prosthetic Treatment Modalities in Implant Dentistry in a Saudi Population
}

\author{
Authors \\ Rahaf Al-Safadi, ${ }^{1,2^{*}}$ Thamer Al-Gannass, ${ }^{2}$ Abdullah Al-Baraki, ${ }^{2}$ Naif Bin Fnais, ${ }^{2}$ \\ Abdullah Abomelha, ${ }^{2}$ Mohammad Al-Shuaibi, ${ }^{2}$ Alfadhel Hamami, ${ }^{2}$ \\ Reem Al-Turki, ${ }^{2}$ Hanin Al-Sugair, ${ }^{2}$ Randa Mohammed ${ }^{2}$ \\ ${ }^{1}$ Department of Preventive Dentistry, College of Dentistry, Riyadh Elm University, Riyadh, Kingdom of \\ Saudi Arabia \\ ${ }^{2}$ University Dental Hospital, College of Dentistry, Riyadh Elm University, Riyadh, Kingdom of Saudi \\ Arabia \\ *Corresponding Author \\ Rahaf Al-Safadi \\ Department of Preventive Dentistry, University Dental Hospital, College of Dentistry, Riyadh Elm \\ University, Riyadh, Kingdom of Saudi Arabia \\ Email: dent.sci.research@gmail.com
}

\begin{abstract}
Aim: The aim of this study was to detect and describe the patterns of implant prosthetic treatment modalities placed in partially and fully edentulous Saudi patients restored with dental implants in Saudi Arabia and to detect the status of the health insurance covering dental implants in Saudi Arabia.

Materials and Methods: 520 Saudi patients aged $\geq 18$ years residing in Saudi Arabia and treated with at least one dental implant done in dental health premises in Saudi Arabia were randomly included in the study. Clinical and radiographic examinations were used to detect implant prostheses types (single-tooth implant, implant-supported long or short span conventional fixed bridge, implant overdenture). The health insurance covering dental implants was detected too. The data obtained including age, gender, systemic disease, and tobacco smoking were documented in a patient examination form then statistically analyzed using Chi-Square Test and U-Test.

Results: The most frequently tooth type replaced by dental implants was the molars (45.5\%), followed by premolars $(40 \%)$, incisors $(7.7 \%)$, and canines (6.8\%); mandibular first molars were the most common tooth type replaced by implants. Single-tooth implant was the most common prosthetic treatment modality (85.2\%), followed by implant-supported short span conventional fixed bridge (9.8\%), implant overdenture $(2.8 \%)$, and implant-supported long span conventional fixed bridge (2.2\%). The majority of implant overdenture prostheses were seen in the age group $\geq 60$ years. Implant-supported long span fixed bridge prostheses were more in patients aged $\geq 50$ years than in patients aged $<50$ years, while single-tooth implant prostheses were more in patients aged $<50$ years than in patients aged $\geq 50$ years. Of all teeth types replaced by dental implants, molars were the most common type seen in implant-supported long span fixed bridges and in single-tooth implants, whereas canines were the most common type seen in overdentures. There was an insignificant difference in the median number of dental implants between males and females.

Conclusion: Single-tooth implant is major. Health insurance policy doesn't cover dental implants in Saudi Arabia.
\end{abstract}

Keywords: Implant, Modalities, Prostheses/Prosthetic, Type 


\section{Introduction}

Since the introduction of the concept of osseointegration, implant dentistry has evolved and revolutionized dental treatment. ${ }^{1-3}$ For instance, dental implants facilitate replacement of a single missing tooth preservatively without violating adjacent tooth structure or bone. ${ }^{3}$ Also, the McGill consensus statement on overdentures concluded that a two-implant-supported overdenture should be considered the primary choice of standard prosthetic treatment for mandibular edentulous patients, thus taking over the conventional complete denture. $^{4}$ In addition to the modern significant functional, biologic, and esthetic advantages that implant therapy provides for many patients when compared with conventional fixed or removable prostheses, dental implant treatment has excellent long-term results, as documented by numerous 10 year studies with success and survival rates $\geq 95 \%{ }^{5-}$ 9; however, fixed partial dentures have an expected survival rate of $87 \%$ and $69 \%$ at 10 and 15 years, respectively. ${ }^{10-12}$ Furthermore, the market research indicates to a general increase in the use of dental implants. ${ }^{2,13}$ Therefore, the aim of this study was to detect the patterns of prosthetic treatment modalities which can vary from a single tooth replacement in a partially dentate case to a full arch reconstruction among Saudi patients restored with dental implants in Saudi Arabia and to detect the status of the health insurance covering dental implants in Saudi Arabia.

\section{Materials and Methods \\ Ethical approval}

The study was registered with the research center of Riyadh Elm University (FRP/2019/124) and received ethical approval from the institutional review board of the same institution (RC/IRB/2019/238).

Selection of the content for analysis and statistical analysis

The inclusion criteria were: 1 . patients aged $\geq 18$ years 2. patients with at least one dental implant 3. Saudi patients residing in the Kingdom of Saudi
Arabia 4. dental implant treatments done in dental health premises (hospitals, polyclinics, private clinics) in the Kingdom of Saudi Arabia. The study was conducted from October 2019 to January 2020. The sample of the study consisted of 520 patients that were randomly selected. After taking the consent of the patient, each patient was clinically examined for the common prosthetic treatment modalities in implant dentistry ${ }^{14-16}$ :

1. Implant overdenture in fully edentulous arch (implant denture supported by implants and largely by mucosal edentulous ridge)

2. Implant-supported long span conventional fixed bridge in fully edentulous arch

3. Single-tooth implant

4. Implant-supported short span conventional fixed bridge in partially edentulous arch

Also, radiographic examination was used including panoramic and periapical radiographs. The health insurance covering the cost of dental implants was detected. Cases were subjected to consultations of experienced implantologists. The data obtained including age, gender, systemic disease, and tobacco smoking were documented in a patient examination form then statistically analyzed using Chi-Square Test to test the association between categorical variables (age, prosthesis type, tooth type replaced by dental implant) and Mann-Whitney-Wilcoxon Test (U-Test) to test the differences in the number of dental implants per patient by (gender, tobacco smoking, systemic disease). All statistical analyses were performed using the IBM SPSS Statistics version 20 data processing software. The significance level was set at $\mathrm{p}<0.05$.

\section{Results}

A total of 1393 dental implants and 1111 implant prostheses were placed in 520 Saudi patients. The sample of 520 patients consisted of $n=180(34.6 \%)$ males and $n=340(65.4 \%)$ females, and the patients were of the following age groups: $18-39$ years $\mathrm{n}=$ $215(41.3 \%), 40-49$ years $n=139$ (26.7\%), 50-59 years $n=110(21.2 \%)$, and $\geq 60 n=56(10.8 \%)$. 


\section{Teeth Types Replaced by Dental Implants}

Chi-Square Test showed that there was a significant difference in the percentages of the teeth types replaced by dental implants $\mathrm{p}=0.000<0.05$. The most frequently tooth type replaced by dental implants was the molars $(45.5 \%)$, followed by premolars $(40 \%)$, incisors $(7.7 \%)$, and canines $(6.8 \%)$. The most frequently tooth type replaced by dental implants was the mandibular first molars $(24.3 \%)$, followed by maxillary first molars (14.3\%), maxillary second premolars $(13.5 \%)$, and maxillary first premolars $(11.4 \%)$. However, the least frequently tooth type replaced by dental implants was the mandibular central incisors $(0.6 \%)$ (Table 1, Table 2, Chart 1).
Table 1: Distribution of Dental Implants by Tooth Type

\begin{tabular}{|l|c|c|}
\hline \multicolumn{1}{|c|}{ Tooth Type } & $\mathrm{n}$ & $\%$ \\
\hline Maxillary Second Molar & 20 & 1.4 \\
Mandibular Second Molar & 76 & 5.5 \\
Maxillary First Molar & 199 & 14.3 \\
Mandibular First Molar & 339 & 24.3 \\
Maxillary Second Premolar & 188 & 13.5 \\
Mandibular Second Premolar & 115 & 8.3 \\
Maxillary First Premolar & 159 & 11.4 \\
Mandibular First Premolar & 95 & 6.8 \\
Maxillary Canine & 53 & 3.8 \\
Mandibular Canine & 42 & 3.0 \\
Maxillary Lateral Incisor & 45 & 3.2 \\
Mandibular Lateral Incisor & 22 & 1.6 \\
Maxillary Central Incisor & 31 & 2.2 \\
Mandibular Central Incisor & 9 & 0.6 \\
Total & 1393 & 100 \\
\hline
\end{tabular}

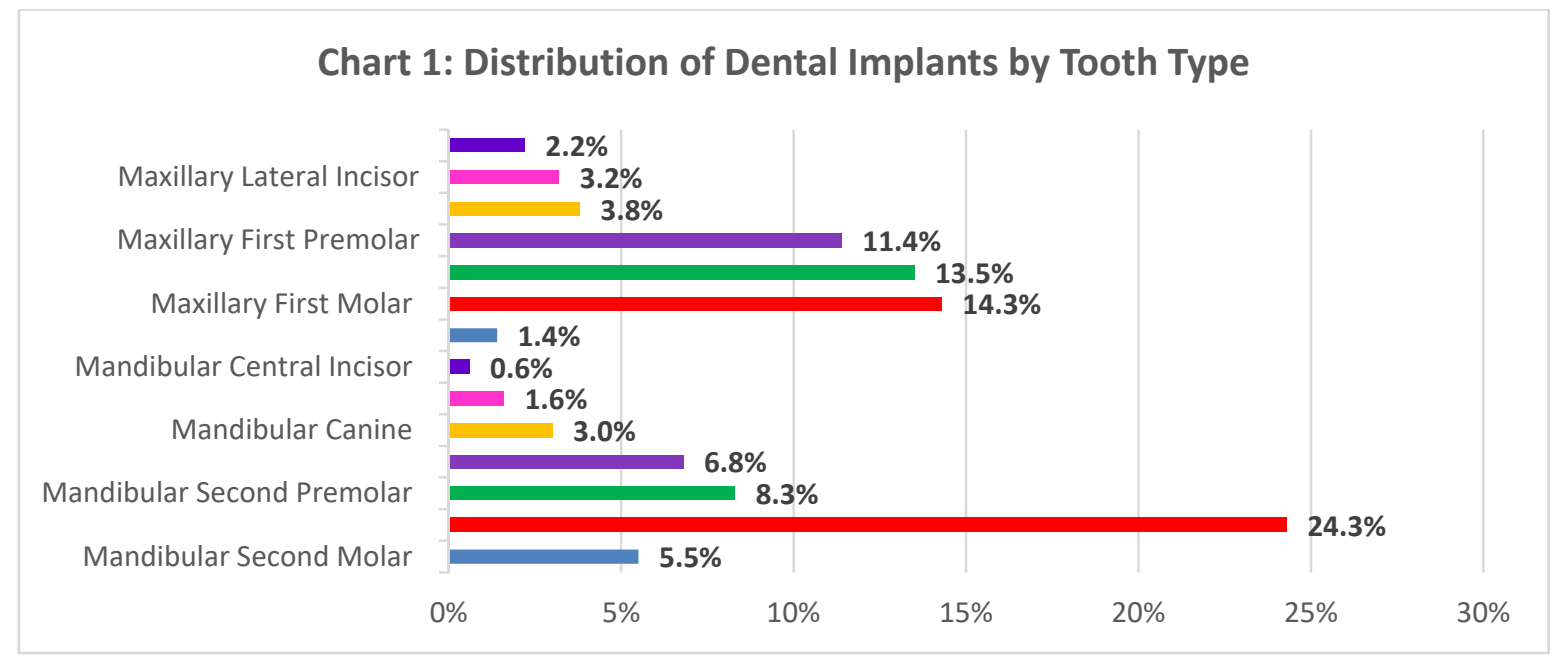

\section{Prosthetic Treatment Modalities and Teeth Types \\ Replaced by Dental Implants}

Chi-Square Test showed that there was a statistically significant relationship between the implant prostheses types and the teeth types replaced by dental implants $p=0.000<0.05$. The Contingency Coefficient value was $(42.5 \%)$ with $p$ $=0.000<0.05$. Of all teeth types replaced by implants, canines were the most common tooth type seen in overdentures $(51.4 \%)$, followed by premolars $(27 \%)$, and molars $(16.2 \%)$. In addition, of all teeth types replaced by implants, molars $(36.6 \%)$ and premolars (32.1\%) were the most commonly seen in implant-supported long span conventional fixed bridges, followed by incisors $(17.2 \%)$, and canines $(14.2 \%)$. Also, of all teeth types replaced by implants, molars were the most common tooth type seen in single-tooth implants $(50.4 \%)$. Moreover, of the total number of dental implants in the study sample, single-tooth implants accounted for the largest number of dental implants $\mathrm{n}=962 \quad(69.1 \%)$, while implant overdentures accounted for the smallest number of dental implants $n=74(5.3 \%)$ (Table 2).

Of all prostheses types, the majority of canines replaced by implants were seen in implant overdenture (40\%). However, of all prostheses types, the majority of incisors and molars replaced by dental implants were seen in single-tooth implant $(48.6 \%) \quad$ and $\quad(76.5 \%), \quad$ respectively. 
Table 2: Implant Prostheses Types and Teeth Types Replaced by Dental Implants

\begin{tabular}{|c|c|c|c|c|c|c|}
\hline \multirow{2}{*}{\multicolumn{2}{|c|}{$\begin{array}{l}\text { Teeth Types } \\
\text { Replaced by } \\
\text { Dental Implants }\end{array}$}} & \multicolumn{4}{|c|}{ Implant Prostheses Types } & \multirow[t]{2}{*}{ Total } \\
\hline & & \multirow{2}{*}{$\frac{\begin{array}{c}\text { Implant } \\
\text { overdenture }\end{array}}{4(5.4)}$} & \multirow{2}{*}{$\begin{array}{c}\begin{array}{c}\text { Long span conventional } \\
\text { fixed bridge }\end{array} \\
23(17.2)\end{array}$} & \multirow{2}{*}{$\begin{array}{c}\begin{array}{c}\text { Single-tooth } \\
\text { implant }\end{array} \\
52(5.4)\end{array}$} & \multirow{2}{*}{$\begin{array}{c}\text { Short span conventional } \\
\text { fixed bridge }\end{array}$} & \\
\hline Incisors & $\mathrm{n}(\%)$ & & & & & $107(7.7)$ \\
\hline Canines & $\mathrm{n}(\%)$ & $38(51.4)$ & $19(14.2)$ & $29(3)$ & $9(4)$ & $95 \quad(6.8)$ \\
\hline Premolars & $\mathrm{n}(\%)$ & $20(27)$ & $43(32.1)$ & $396(41.2)$ & $98(43.9)$ & $557(40)$ \\
\hline Molars & $\mathrm{n}(\%)$ & $12(16.2)$ & $49(36.6)$ & $485(50.4)$ & $88(39.5)$ & $634(45.5)$ \\
\hline Total & $\mathrm{n}(\%)$ & $74(5.3)$ & $134(9.6)$ & $962(69.1)$ & $223(16)$ & $1393(100)$ \\
\hline
\end{tabular}

\section{Prosthetic Treatment Modalities}

Chi-Square Test showed that there was a significant difference in the percentages of implant prostheses types $\mathrm{p}=0.000<0.05$. Therefore, single-tooth implant was the most common prosthesis type $n=$ 947 (85.2\%), followed by implant- supported short

span conventional fixed bridge $\mathrm{n}=109$ (9.8\%), implant overdenture $\mathrm{n}=31(2.8 \%)$, and implantsupported long span conventional fixed bridge $\mathrm{n}=$ $24(2.2 \%)$ (Chart 2).

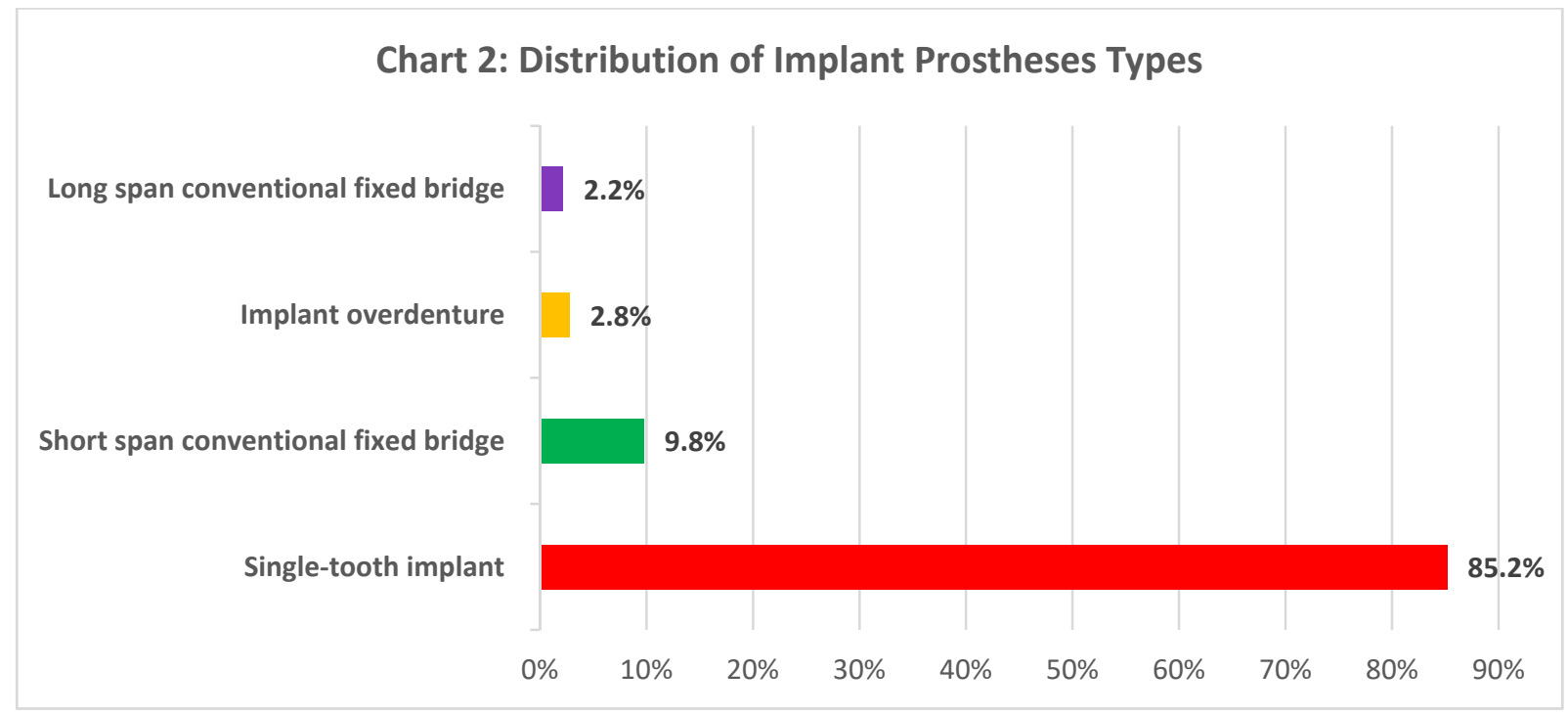

\section{Percentages of Dental Implants and Age Groups}

Chi-Square Test Showed that there was a significant difference in the percentages of dental implants among age groups $\mathrm{p}=0.000<0.05$ (Table 3 ).

Table 3: Number of Dental Implants and Age Groups

\begin{tabular}{|ccc|}
\hline $\begin{array}{c}\text { Age } \\
\text { Group, } \\
\text { Years }\end{array}$ & $\begin{array}{c}\text { Dental } \\
\text { Implants } \\
(\mathrm{n})\end{array}$ & $\begin{array}{c}\text { Dental } \\
\text { Implants } \\
(\%)\end{array}$ \\
\hline $18-39$ & 435 & 31.2 \\
$40-49$ & 357 & 25.6 \\
$50-59$ & 327 & 23.5 \\
$\geq 60$ & 274 & 19.7 \\
Total & 1393 & 100 \\
\hline
\end{tabular}

\section{Prosthetic Treatment Modalities and Age Groups} Chi-Square Test showed that there was a statistically significant relationship between the implant prostheses types and the age of the patient $p=0.000$ $<0.05$. The Contingency Coefficient value was $(42.2 \%)$ with $\mathrm{p}=0.000<0.05$. Of all age groups, the majority of implant overdenture prostheses were seen in the age group $\geq 60$ years $(71 \%)$, while none of them were seen in the age group 18-39 years. Also, of all age groups, implant-supported long span fixed bridge prostheses were more in patients $\geq 50$ years of age than in patients $<50$ years of age, and the majority of them were seen in the age group $\geq 60$ years $(70.8 \%)$. However, of all age groups, singletooth implant prostheses were more in patients $<50$ 
years of age than in patients $\geq 50$ years of age, and

18-39 years $(40.7 \%)$ (Table 4$)$.

the majority of them were seen in the age group

Table 4: Implant Prostheses Types and Age Groups

\begin{tabular}{|c|c|c|c|c|c|c|}
\hline \multirow{2}{*}{\multicolumn{2}{|c|}{$\begin{array}{l}\text { Age Group, } \\
\text { Years }\end{array}$}} & \multicolumn{4}{|c|}{ Implant Prostheses Types } & \multirow[t]{2}{*}{ Total } \\
\hline & & Overdenture & \multirow{2}{*}{$\begin{array}{c}\text { Long span } \\
\text { conventional fixed } \\
\text { bridge }\end{array}$} & $\begin{array}{l}\text { Single-tooth } \\
\text { implant }\end{array}$ & $\begin{array}{c}\text { Short span } \\
\text { conventional } \\
\text { fixed bridge } \\
\end{array}$ & \\
\hline $18-39$ & $\mathrm{n}(\%)$ & $0(0)$ & & $385(40.7)$ & $23(21.1)$ & $409(36.8)$ \\
\hline $40-49$ & $\mathrm{n}(\%)$ & $6(19.4)$ & $2(8.3)$ & $271(28.6)$ & $25(22.9)$ & $304(27.4)$ \\
\hline $50-59$ & $\mathrm{n}(\%)$ & $3(9.7)$ & $4(16.7)$ & $228(24.1)$ & $32(29.4)$ & $267(24)$ \\
\hline$\geq 60$ & $\mathrm{n}(\%)$ & $22(71)$ & $17(70.8)$ & $63(6.7)$ & $29(26.6)$ & $131(11.8)$ \\
\hline Total & $\mathrm{n}(\%)$ & $31(2.8)$ & $24(2.2)$ & $947(85.2)$ & $109(9.8)$ & $1111(100)$ \\
\hline
\end{tabular}

\section{Prosthetic Treatment Modalities and Jaws}

Chi-Square Test showed that there was an insignificant relationship between the implant prostheses types and the jaws of the patient (maxilla / mandible) $\mathrm{p}=0.527>0.05$.

\section{Dental Implants and Jaws}

Chi-Square Test showed that there was an insignificant difference in the percentages of the dental implants between the maxilla and the mandible $\mathrm{p}=0.688>0.05$.

\section{Dental Implants and Gender}

U-Test showed that there was an insignificant difference in the median number of dental implants between males and females $p=0.155>0.05$.

\section{Dental Implants and Tobacco Smoking}

U-Test showed that there was an insignificant difference in the median number of dental implants between smokers and nonsmokers $\mathrm{p}=0.444>0.05$.

\section{Dental Implants and Systemic Diseases}

U-Test showed that there was an insignificant difference in the median number of dental implants between healthy patients and patients with systemic diseases as the following: diabetes mellitus $\mathrm{p}=$ $0.159>0.05$, osteoporosis $p=0.961>0.05$, cardiovascular disease (CVD) $\mathrm{p}=0.650>0.05$, hypertension $\mathrm{p}=0.402>0.05$, asthma $\mathrm{p}=0.233>$ 0.05 , renal disease $\mathrm{p}=0.259>0.05$.

\section{Discussion}

According to the regulations of the Council of Cooperative Health Insurance in the Kingdom of Saudi Arabia, the health insurance policy does not cover the cost of dental implants. ${ }^{17,18}$ Therefore, all the patients included in this study sample didn't have health insurance that covered dental implants. The present study is consistent with Elani et $\mathrm{al}^{2}$ who found that among adults missing at least one tooth and aged $\geq 18$ years in the USA most dental implants were placed in posterior sites, and mandibular first molars were the most common tooth type replaced by implants, followed by maxillary first molars. Also, in the USA, Elani and colleagues found that roughly half the implants were placed in the mandible $(51 \%, 95 \% \mathrm{CI}=45 \%$ to $57 \%)$ and half in the maxilla $(49 \%, 95 \% \mathrm{CI}=43 \%$ to $55 \%),{ }^{2}$ and the present study found no difference between the maxilla and the mandible with respect to the number of dental implants. In Saudi Arabia, Al-Safadi and colleagues found that the highest percentage of extracted teeth was observed in the posterior region, ${ }^{19}$ and with the exclusion of third molars, mandibular first molars were the most frequently extracted tooth type, followed by maxillary first molars ${ }^{20}$; these findings may be a justification to the results of the present study.

In this study, molars and premolars were the most common teeth types replaced by implants in implant-supported long span conventional fixed bridges, whereas canines were the most common tooth type replaced by implants in overdentures; this 
result was in accordance with the recommendations of many clincians. ${ }^{14,15,21}$

Periodontitis is the major risk factor for implant failure, followed by tobacco smoking. ${ }^{22}$ The effect of smoking on the implant survival rate and failure rate have been tested by several studies, and the majority of these studies confirmed the negative impact of smoking on implant therapy. For instance, an increased failure rate in smokers compared with nonsmokers was found with a failure rate 2-2.5 times higher in smokers. ${ }^{23}$ Numerous factors were found to have an impact on the effect of smoking on implant therapy outcomes such as the degree of smoking exposure (the number of cigarettes smoked and the duration of smoking), the anatomic location of implant placement (maxilla or mandible or near augmented sinuses or ridges), and the implant surface. ${ }^{23}$ For instance, very good nominees for implant failure are heavy smokers. ${ }^{15}$ Also, in smokers, maxillary implants are more susceptible to smoking and have higher failure rates than mandibular ones which could be explained by the different bone density between the maxilla and the mandible. In addition, both implants placed in sites augmented by bone grafting and those placed in sites of native bone have similar survival rates, but smoking may be a major factor in changing the outcome of implant therapy in augmented sites. With respect to implant surface, the survival of machined surface implants is negatively affected by smoking to a greater degree than that of rough surface implants, and rough or microroughened surface characteristics of dental implants may palliate the negative side effects of smoking on long-term implant end result. ${ }^{23}$

Diabetes has a negative impact on the vasculature, healing, and susceptibility to infection. $^{15,23}$ Also, uncontrolled or poorly controlled diabetes is a major risk factor for periimplant bone loss, ${ }^{24}$ thus implant failure. ${ }^{15,23}$ However, well-controlled diabetic patients haven't shown an increased implant failure rate. ${ }^{15,23}$

Cardiovascular disease (CVD) such as hypertension, atherosclerosis, vascular stenosis, coronary artery disease, and congestive heart failure have direct impact on oxygen and nutrition supply to tissues. ${ }^{23}$ However, in a study of a small sample size, Khadivi and colleagues suggested that CVD may not be a risk factor for successful osseointegration. $^{25}$ Also, Moy et $\mathrm{al}^{26}$ found that hypertension and asthma were not correlated with a significant increase in failure of dental implants; however, diabetes and tobacco smoking were significant predictors to implant failure, and failure rates significantly increased in smokers and diabetic patients. In diabetic patients failures started from the first few months and continued over the following 10 years; in smokers, most failures occurred within the first year, with very few failing at later time points. ${ }^{26}$

Osteoporosis is not contraindication to implant therapy, ${ }^{15,23,27-29}$ and some authors have compared osteoporotic bone to the proposed model of bone type four. ${ }^{15,29}$ In addition, osteoporotic patients treated with oral bisphosphonates which is an antiresorptive medication have low risk of developing osteonecrosis, ${ }^{15,29}$ but there is a high risk of osteonecrosis in patients receiving intravenous bisphosphonates. ${ }^{15,23}$

On the other hand, renal disease is a major concern to implant dentistry because patients who have any chronic renal problems could suffer from poor wound healing, possible alteration in bone structural integrity, and increased risk of infection..$^{30,31}$

\section{Conclusion}

The results of this study showed that single-tooth implant was the most common prosthesis type. According to the regulations of the Council of Cooperative Health Insurance in the Kingdom of Saudi Arabia, the health insurance policy does not cover the cost of dental implants.

\section{Funding: None}

Conflict of Interest: None declared 


\section{References}

1. Brånemark PI, Adell R, Breine U, Hansson BO, Lindström J, Ohlsson A. Intra-osseous anchorage of dental prostheses: I. Experimental studies. Scand J Plast Reconstr Surg. 1969;3(2):81-100.

2. Elani HW, Starr JR, Da Silva JD, Gallucci GO. Trends in dental implant use in the U.S., 19992016, and projections to 2026. J Dent Res. 2018;97(13):1424-1430.

3. Forum SJ. Implant complications: scope of the problem. In: Forum SJ, ed. Dental Implant Complications: Etiology, Prevention, and Treatment. Oxford: Wiley-Blackwell; 2010:1-8.

4. Feine JS, Carlsson GE, Awad MA, et al. The McGill consensus statement on overdentures. Mandibular two-implant overdentures as first choice standard of care for edentulous patients. Gerodontology. 2002;19(1):3-4.

5. Buser D, Sennerby L, De Bruyn H. Modern implant dentistry based on osseointegration: 50 years of progress, current trends and open questions. Periodontol 2000. 2017;73(1):7-21.

6. Buser D, Janner SF, Wittneben JG, Brägger U, Ramseier CA, Salvi GE. 10-year survival and success rates of 511 titanium implants with a sandblasted and acid-etched surface: a retrospective study in 303 partially edentulous patients. Clin Implant Dent Relat Res. 2012;14(6):839-851.

7. Degidi M, Nardi D, Piattelli A. 10-year follow-up of immediately loaded implants with TiUnite porous anodized surface. Clin Implant Dent Relat Res. 2012;14(6):828-838.

8. Fischer K, Stenberg T. Prospective 10-year cohort study based on a randomized controlled trial (RCT) on implant-supported full-arch maxillary prostheses. Part 1: sandblasted and acid-etched implants and mucosal tissue. Clin Implant Dent Relat Res. 2012;14(6):808-815.

9. Gotfredsen K. A 10-year prospective study of single tooth implants placed in the anterior maxilla. Clin Implant Dent Relat Res. 2012;14(1):80-87.

10. Jivraj S, Chee W. Rationale for dental implants. Br Dent J. 2006;200(12):661-665.

11. Scurria MS, Bader JD, Shugars DA. Metaanalysis of fixed partial denture survival: prostheses and abutments. J Prosthet Dent. 1998;79(4):459464.

12. Walton TR. An up to 15-year longitudinal study of 515 metal-ceramic FPDs: Part 1. outcome. Int $J$ Prosthodont. 2002;15(5):439-445.

13. Murray CM, Thomson WM, Leichter JW. Dental implant use in New Zealand: A 10-year update. $N Z$ dent J. 2016;112(2):49-54.

14. Palmer RM, Smith BJ, Howe LC, Palmer PJ, eds. Implants in Clinical Dentistry. London: Martin Dunitz; 2002.

15. Palmer RM, Howe LC, Palmer PJ, eds. Implants in Clinical Dentistry. $2^{\text {nd }}$ ed. London: Informa Healthcare; 2012.

16. Sonis ST, ed. Dental Secrets. $4^{\text {th }}$ ed. St. Louis, Missouri: Elsevier; 2015.

17. Help and Support / Frequently Asked Questions: Does the cooperative health insurance policy cover alternative body organs transplants that replace any organ in whole or in part?. Council of Cooperative Health

Insurance. https://www.cchi.gov.sa/en/Help/FAQ/Pages/default .aspx?PageIndex=4. Accessed December 14, 2019.

18. Frequently Asked Questions: Does the cooperative health insurance policy cover alternative body organs transplants that replace any organ in whole or in part?. Council of Cooperative Health

Insurance. https://www.cchi.gov.sa/en/Insureds/FAQ/Pages/FA Q-38.aspx. Published July 23, 2018. Accessed December 14, 2019.

19. Al-Safadi R, Al-Safadi R, Al-Safadi R, et al. Prevalence of and reasons for tooth loss in a Saudi population. Int $J$ Emerg Trends Sci Technol. 2019;6(2):6774 -6786.

20. Al-Safadi R, Al-Safadi R, Al-Safadi R, et al. Patterns of and reasons for permanent tooth extractions in a Saudi population. Int $J$ Emerg Trends Sci Technol. 2019;6(5):6811-6821.

21. ELsyad MA, Elsaadawy MG, Abdou AM, Habib AA. Effect of different implant positions on strain developed around four implants supporting a mandibular overdenture with rigid telescope copings. Quintessence Int. 2013;44(9):679-686. 
22. Buhara O, Pehlivan S. Estimating the importance of significant risk factors for early dental implant failure: a Monte Carlo simulation. Int J Oral Maxillofac Implants. 2018;33(1):161-168.

23. Rose LF, Mealey BL. Implant complications associated with systemic disorders and medications.

In: Forum SJ, ed. Dental Implant Complications: Etiology, Prevention, and Treatment. Oxford:

Wiley-Blackwell; 2010:9-45.

24. Byrne G, ed. Fundamentals of Implant Dentistry. Ames, Iowa: John Wiley \& Sons; 2014.

25. Khadivi V, Anderson J, Zarb GA. Cardiovascular disease and treatment outcomes with osseointegration surgery. $J$ Prosthet Dent. 1999;81(5):533-536.

26. Moy PK, Medina D, Shetty V, Aghaloo TL. Dental implant failure rates and associated risk factors. Int $J$ Oral Maxillofac Implants. 2005;20(4):569-577.

27. Wagner F, Schuder K, Hof M, Heuberer S, Seemann R, Dvorak G. Does osteoporosis influence the marginal peri-implant bone level in female patients? A cross-sectional study in a matched collective. Clin Implant Dent Relat Res. 2017;19(4):616-623.

28. Walter C, Al-Nawas B, Wolff T, Schiegnitz E, Grötz KA. Dental implants in patients treated with antiresorptive medication - a systematic literature review. Int J Implant Dent. 2016;2(1):9.

29. Venkatakrishnan CJ, Bhuminathan S, Chandran CR, Poovannan S. Dental implants in patients with osteoporosis - a review. Biomed Pharmacol J. 2017;10(3):1415-1418.

30. El Askary A. Diagnostic considerations for esthetic implant therapy. In: El Askary A, ed. Fundamentals of Esthetic Implant Dentistry. Oxford: Blackwell Munksgaard; 2007:13-78.

31. Yuan Q, Xiong QC, Gupta M, et al. Dental implant treatment for renal failure patients on dialysis: a clinical guideline. Int $J$ Oral Sci. 2017;9(3):125-132. 